ISSN 1029-8940 (Print)

ISSN 2524-230X (Online)

УДК 598.244.2:502.2.05

https://doi.org/10.29235/1029-8940-2019-64-4-472-477

Поступила в редакцию 14.11.2018

Received 14.11.2018

\author{
А. В. Черноморец \\ Научно-практический ичентр НАН Беларуси по биоресурсам, Минск, Республика Беларусь

ДИНАМИКА ЧИСЛЕННОСТИ, УСПЕШНОСТИ РАЗМНОЖЕНИЯ
И ТЕРРИТОРИАЛЬНОГО РАСПРЕДЕЛЕНИЯ БЕЛОГО АИСТА
В ЦЕНТРАЛЬНОЙ ЧАСТИ БЕЛАРУСИ

Аннотация. Представлены результаты анализа популяционных показателей (численности и плотности гнездования, территориального распределения, успешности размножения, использования различных видов опор для гнездования) белого аиста на территории постоянного мониторингового стационара площадью 100 км², расположенного в Воложинском районе Минской области, за период с 2004 по 2018 г. За время исследований на мониторинговом участке отмечено значительное снижение гнездовой численности белого аиста и среднего размера выводка. Также существенно изменились предпочтения в использовании разного типа опор для постройки гнезд. В первую половину периода исследования гнезда располагались преимущественно на деревьях, но с каждым года все больше гнездящихся пар используют для гнездования столбы линий электропередачи (ЛЭП). В связи повышенным риском аварий из-за роста частоты использования хозяйственно важных конструкций для строительства гнезд и возрастанием вероятности гибели самих птиц от электроповреждений предпринимаются меры по предотвращению использования ЛЭП. В то же время наличие указанных отрицательных трендов позволяет сделать неблагоприятный прогноз для популяции.

Ключевые слова: белый аист, Ciconia ciconia, численность, плотность гнездования, успешность размножения, динамика

Для цитирования: Черноморец, А.В. Динамика численности, успешности размножения и территориального распределения белого аиста в центральной части Беларуси / А. В. Черноморец // Вес. Нац. акад. навук Беларусі. Сер. біял. навук. - 2019. - Т. 64, № 4. - С. 472-477. https://doi.org/10.29235/1029-8940-2019-64-4-472-477

\title{
A.V. Chernomorets
}

Scientific and Practical Center for Bioresources of the National Academy of Sciences of Belarus, Minsk, Republic of Belarus

\section{DYNAMICS OF NUMBER, SUCCESS OF REPRODUCTION AND TERRITORIAL DISTRIBUTION OF WHITE STORK IN THE CENTRAL PART OF BELARUS}

\begin{abstract}
The results of White Stork Ciconia ciconia study on monitoring plot (area of $100 \mathrm{~km}^{2}$, Volozhin district, Minsk Region) in 2004-2018 are analyzed: numbers, spatial distribution, breeding success and location of nests on different supports. Decrease of numbers, significant reduction of breeding success and grow the rate of using electric pylons for nesting are allowed to make an unfavourable prognosis for population.

Keywords: White Stork, Ciconia ciconia, numbers, nesting density, breeding success, dynamics

For citation: Chernomorets A. V. Dynamics of number, success of reproduction and territorial distribution of White Stork in the central part of Belarus. Vestsi Natsyyanal'nai akademii navuk Belarusi. Seryya biyalagichnych navuk = Proceedings of the National Academy of Sciences of Belarus. Biological series, 2019, vol. 64, no. 4, pp. $472-477$ (in Russian). https://doi.org/10.29235/1029-8940-2019-64-4-472-477
\end{abstract}

Введение. Белый аист - один из наиболее хорошо изученных видов птиц. Данные исследования представляют не только познавательный интерес, но и имеют практическую значимость. Аисты играют важную роль не только в населяемых ими природных сообществах. Обитая по соседству с людьми, они оказывают заметное влияние и на многие отрасли хозяйственной деятельности человека. Кроме того, вследствие относительно высокой численности и положения у вершины трофической пирамиды белый аист имеет большое индикационное значение при оценке степени трансформации биоценозов в связи с мелиорацией и другими видами антропогенного воздействия. В связи с этим результаты мониторинга белого аиста могут быть исполь-

(C) Черноморец А. В., 2019 
зованы для разработки подходов по охране и управлению нарушенных ценных местообитаний, снижению рисков и угроз для популяции вида, связанных с последствиями широкомасштабной мелиорации, с урбанизацией, интенсификацией сельского хозяйства, развитием энергетики, а также для экологического воспитания и просвещения населения [1]. Долговременные мониторинговые исследования на одних и тех же контрольных участках позволяют накапливать данные о состоянии отдельных гнездовых группировок, на основе которых далее оценивается динамика основных популяционных показателей, проводится сравнительный анализ состояния вида в различных местообитаниях и регионах [2-4].

Цель исследования - анализ динамики основных популяционных показателей белого аиста (численности и плотности гнездования, территориального распределения, успешности размножения, использования различных видов опор для гнездования) на мониторинговом участке в центральной Беларуси.

Условия обитания вида в центральной части Беларуси позволяют отнести территорию региона к субоптимальным местобитаниям ввиду того, что показатели плотности гнездования вида и успешности размножения несколько выше средних по стране [4]. Одни из самых высоких в стране показателей гнездования аистов на протяжении последних десятилетий регистрировали в пойме р. Припять, где многолетние исследования проводили с начала 1990-х годов [2]. Анализ результатов абсолютных учетов для центральной части Беларуси до недавнего времени не проводили, однако благодаря накопленному к настоящему времени материалу появилась возможность не только оценить условия обитания белого аиста в центральной части Беларуси, но и сравнить эти данные с результатами учета в других регионах страны.

Материалы и методы исследования. В настоящей работе использованы результаты абсолютных учетов, которые были проведены с 2004 г. на территории общей площадью около 100 км $^{2}$ на западе Воложинского района Минской области (рис. 1).

В пределах стационара расположено 18 населенных пунктов сельского типа. По территории данного мониторингового участка протекает р. Западная Березина, являющаяся правым притоком р. Неман. Лесистость территории участка составляет около 50 \%, значительная часть открытых пространств представлена сельскохозяйственными угодьями, площадь открытых пойменных участков несущественна. В свою очередь в пойме р. Припять условия обитания обеспечивают одни из самых высоких показателей гнездования аистов. Оптимальные условия обеспечиваются

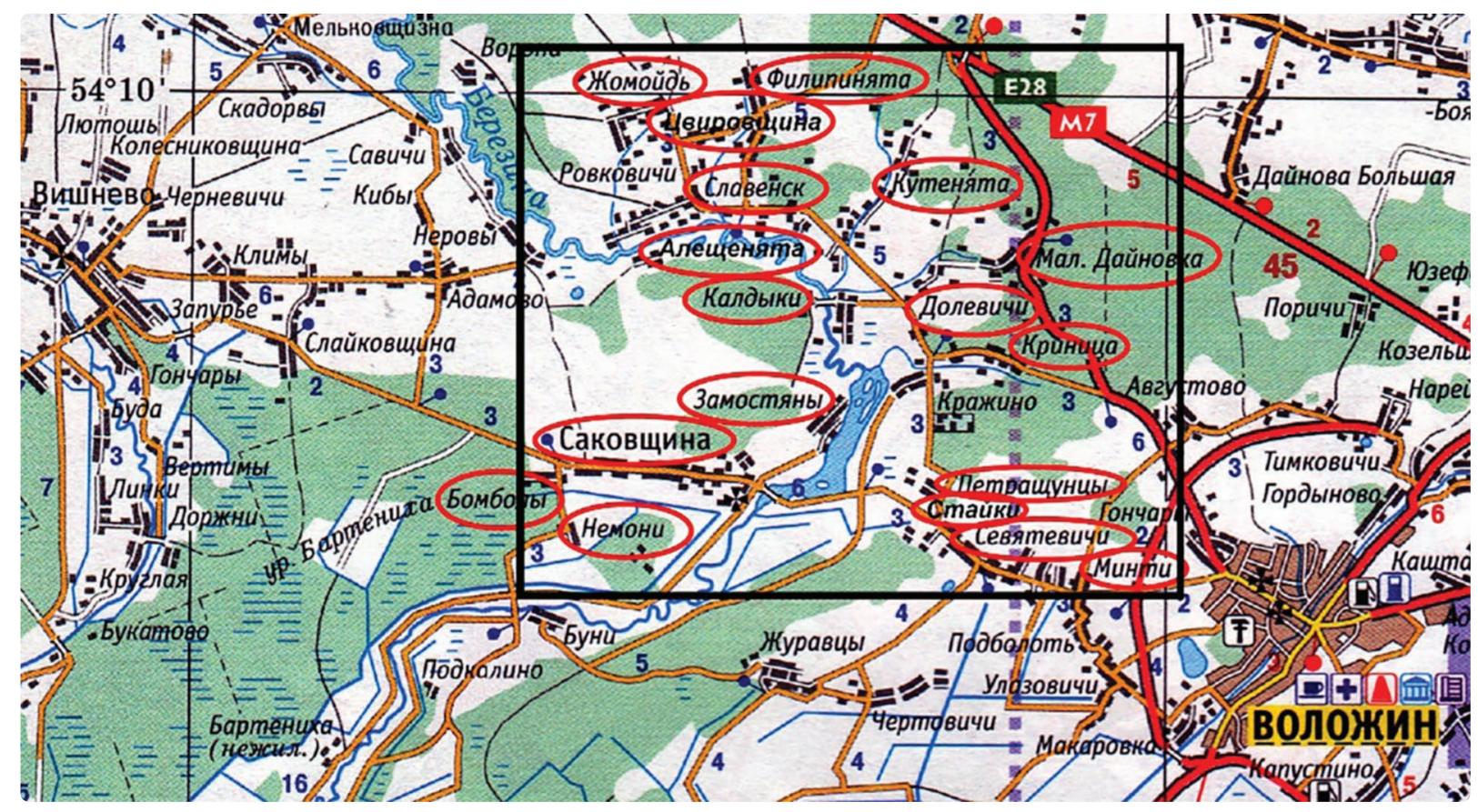

Рис. 1. Схема Воложинского стационара

Fig. 1. The scheme of Volozhin plot 
большой площадью открытых территорий, представленных в основном сельхозугодьями, и значительными по площади участками пойменных лугов. Однако для данной территории существует ряд проблем, вызванных осушением большей части болот в водосборе реки и сужением отдельных участков поймы в процессе ее обвалования для предупреждения наводнений, а также определенными изменениями масштабов сельскохозяйственной деятельности [2].

Полевые работы проводили ежегодно, и в разные годы к ним привлекались студенты биологического факультета БГУ во время прохождения полевой практики под руководством преподавателей на геостанции «Западная Березина». Сбор полевых данных в последние четыре года (2015-2018 гг.), а также обработка и анализ ранее полученной информации осуществлены непосредственно автором. Исходные данные учетов за 2011 г. были утеряны, поэтому не включены в общий анализ.

Полевые работы на стационаре заключались в учетах гнезд белого аиста, определении характера их занятости и расположения на различных опорах, а также в выявлении количества слетков в выводках накануне вылета. Сбор материала проводили с конца июня до середины - конца июля. При сборе и анализе популяционных показателей использована общепринятая международная методика, согласно которой гнездящейся считалась пара (HPa), занимающая гнездо не менее половины гнездового периода, т. е. 1,5 мес. $[5,6]$. За неуспешную принимали гнездящуюся пару, по различным причинам не имеющую вылетевших из гнезда птенцов (НР0). Информацию о причинах неуспеха гнездования в более ранний период собирали путем опроса местного населения. Для характеристики успеха размножения рассчитывали среднее количество слетков на гнездящуюся пару (JZa) и на успешную пару (JZm), а также долю неуспешных пар в процентах $(\% \mathrm{HP} 0)$. Плотность гнездования рассчитывали как соотношение количества гнездящихся пар на

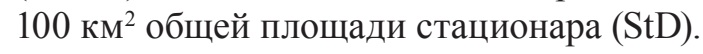

Статистическая обработка материала проведена при помощи программы Statistica 7.0. Достоверными считались различия и выявленные зависимости при уровне значимости $p<0,05$.

Результаты и их обсуждение. На территории мониторинговой площадки в Воложинском районе занятые гнезда белых аистов регистрировали в разные годы в 16 из 18 населенных пунктов, ни разу не были отмечены лишь в двух из них - Малой Дайновке и Жомойди. В разные годы плотность гнездования вида изменялась в пределах 14,0-26,0 гн. пары/100 км² общей площади. Данный показатель несколько выше, чем средний по стране, рассчитанный для территории всех мониторинговых площадок - 17,9 гн. пары/100 км² в 2014-2015 гг. Однако он ниже, чем в оптимальных для вида местообитаниях в пойме р. Припять с более высокой площадью открытых местообитаний и значительной обводненностью всей территории [3].

Как видно на рис. 2, численность белого аиста на территории Воложинского стационара подвержена значительным колебаниям. И если с 2009 по 2012 г. наблюдался ее существенный подъем максимум до 26 гнездящихся пар, то в последние годы их количество здесь значительно уменьшилось, достигнув минимума за весь период наблюдений - 14 гнездящихся пар. Продолжающееся сокращение численности вида в последние годы связано с крайне низким успехом размножения аистов в предыдущие годы.

В среднем в разные годы на один населенный пункт приходилось от 0,8 до 1,4 гнездящейся пары белого аиста. Максимальное их количество ежегодно регистрировалось в а. г. Саковщина от 5 пар в 2015-2016 гг. до 11 пар в 2010 г. В целом за последние 14 лет в пределах мониторингового участка наблюдается территориальное перераспределение белого аиста на гнездовании. Так, в трех населенных пунктах аисты вообще перестали гнездиться (деревни Алещенята, Криница, Минти), и наоборот, появились на гнездовании в д. Севятевичи, где в первую половину периода наших исследований не регистрировались. Причинами территориального перераспределения послужили биотопические изменения, вызванные сужением и зарастанием отдельных участков поймы Западной Березины, сокращением масштабов сельскохозяйственной деятельности на отдельных участках, а также антропогенный фактор (разрушение гнезд).

Средний размер выводка за последние годы стремительно уменьшался $(p<0,001)$ : с 3,06 птенца на гнездящуюся пару в 2004 г. до 1,31 птенца в 2016 г. (рис. 3). Для успешных пар этот показатель также значительно снизился - с 3,24 птенца на пару в 2004 г. до 1,91 птенца в 2016 г., хотя в 2017-2018 гг. данный показатель несколько увеличился - до 2,07 и 1,85 птенца соответственно. 


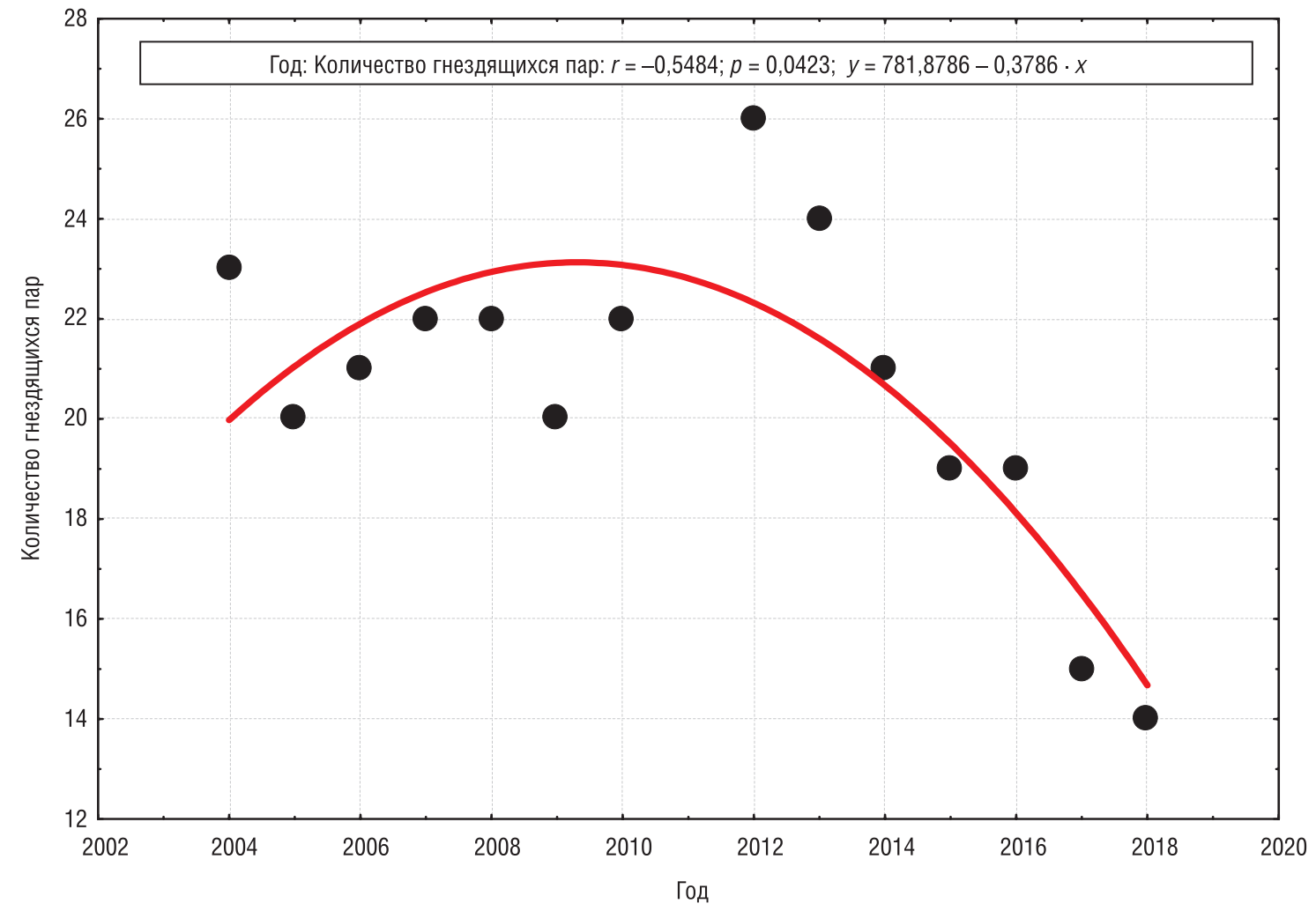

Рис. 2. Динамика численности белого аиста на Воложинском стационаре в 2004-2018 гг.

Fig. 2. Dynamics of White Stork number at Volozhin plot in 2004-2018

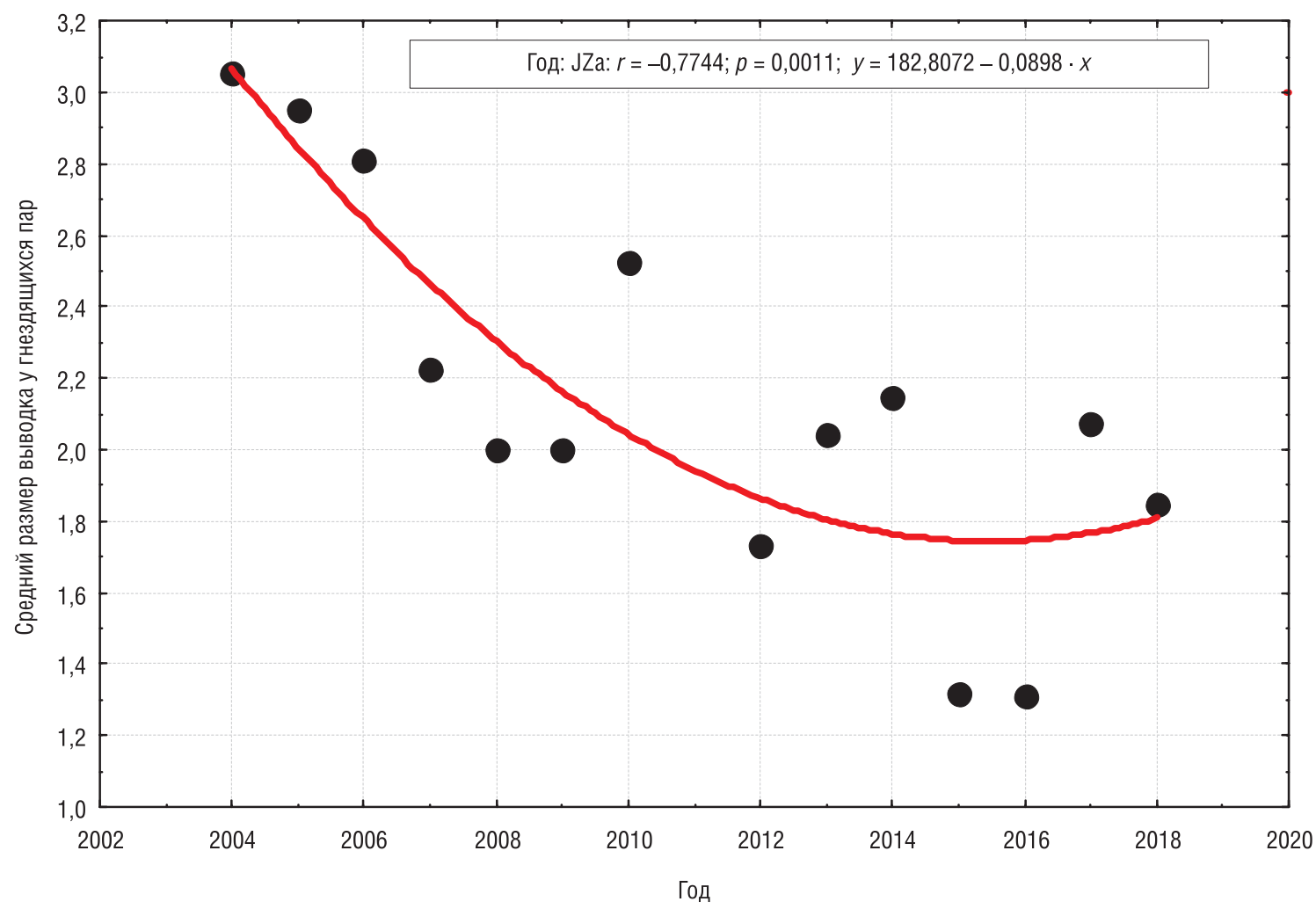

Рис. 3. Динамика среднего размера выводка гнездящихся пар белого аиста на Воложинском стационаре в 2004-2018 гг.

Fig. 3. Dynamics of average brood size in breeding pairs of White Stork at Volozhin plot in 2004-2018 
Крайне низкий успех размножения в 2015-2016 гг., вероятно, вызван продолжительным периодом засухи, а улучшение успешности гнездования на протяжении последних двух сезонов размножения можно связать с более благоприятными климатическими и погодными условиями не только на территории стационара, но и в целом по стране.

О снижении репродуктивного успеха на территории мониторинговой площадки говорит и другой показатель: за время наших наблюдений в Воложинском районе постоянно росла доля неуспешных пар $(p<0,05)$. Если с 2004 по 2010 г. она варьировалась в пределах 4,8-15,0 \%, то с 2012 по 2016 г. не имели потомства от 9,5 до 37,0 \% приступивших к гнездованию пар. Основными причинами неуспешного гнездования были неблагоприятные погодные условия (сильный ветер, ливни), выбрасывание яиц или птенцов самими птицами (как реакция на ухудшение кормовой базы), а также разрушение гнезд на «нежелательных» для человека опорах. В 2017-2018 гг. все гнездящиеся пары имели вылетевших из гнезд птенцов, что говорит о некотором улучшении условий обитания вида.

На территории Воложинского стационара белые аисты гнездятся преимущественно на деревьях, опорах ЛЭП и водонапорных башнях. Так, если в первую половину периода наших исследований около 2/3 аистов гнездилось на деревьях, то к 2018 г. доля таких гнезд сократилась до 42,9 \%. Единственный случай устройства гнезда на крыше жилого дома был отмечен в а. г. Саковщина в 2015 г. Доля гнезд на водонапорных башнях за весь период исследований составила от 4,5 до 10,0 \%. Напротив, стремительными темпами увеличивается количество птиц, гнездящихся на опорах ЛЭП: доля таких гнезд возросла в 3 раза - от 8,7 \% в 2004 г. до 42,9 \% в 2016 г. Такое явление, как смена предпочитаемых типов гнездовых опор, характерно для популяции белого аиста в целом, в том числе на территории Беларуси, хотя в отдельных регионах могут быть свои особенности, например в скорости данного процесса. В частности, до недавнего времени в центральной части Беларуси преобладающим типом опор являлись деревья, но с каждым годом доля таких гнезд уменьшается [2, 3].

Происходящие в выборе гнездовых опор изменения для группировки вида в центральной части Беларуси могут негативно отразиться на состоянии популяции вида, поскольку с ростом частоты использования для строительства гнезд хозяйственно важных конструкций усиливаются меры со стороны человека по предотвращению их использования из-за повышенного риска аварий на ЛЭП, возрастает вероятность гибели самих птиц от электроповреждений.

Заключение. В целом по результатам мониторинга белого аиста на территории площадки в Воложинском районе в 2004-2018 гг. можно судить о наблюдающемся в последние годы ряде негативных процессов. В частности, это выражается в сокращении численности вида при некотором территориальном перераспределении в границах участка. Значительное снижение репродуктивного потенциала во многом обусловлено естественными причинами, однако все более частое использование аистами для гнездования столбов ЛЭП усиливает негативное воздействие на популяцию антропогенных факторов.

Благодарности. Автор выражает благодарность преподавателям кафедры зоологии и кафедры общей экологии и методики преподавания биологии В.В. Гричику, А.В. Балашу, В.В. Сахвону, а также студентам биологического факультета БГУ, в различное время принимавшим участие в сборе информации о белом аисте на территории стационара: О.В. Лукшиц, И. И. Ротенко, М.Ю. Соловьевой, Е.М. Яшченко, О.М. Волоткевич, О. В. Гусаровой, О. С. Ежовой, Т. П. Липинской, Н. В. Удавидчик, А.В. Юрченко, В.А. Яковлеву, В.А. Асива, А.В. Костюкович, М.О. Стрельциной, С.И. Ханкевич, Л. А. Лекунович, Ю. М. Богдан, Я.К. Минич, Ю. П. Ефимович, В.А. Мищенкову, Е.З. Гицевич, Т.Е. Коляго, Т. Г. Дунец, А.Р. Мамедову, Д.В. Посредник, Т. Г. Гакун, В.С. Костюниной, А.Е. Макаревич, Д.П. Ермакович, Д. А. Рамзаевой, Е.С. Синявской и А. А. Ветошкину.

Особую благодарность автор выражает И.Э. Самусенко за ценные советы при планировании исследования и за рекомендации по оформлению статьи.
Acknowledgements. The author expresses his gratitude to the lecturers of the Department of Zoology and the Department of General Ecology and the Metodology of Teaching Biology V. V. Grichik, A. V. Balash, V. V. Sahvon, as well as students of the Biological Faculty of the Belarusian State University who took part at various times information about the white stork in the hospital: O. V. Lukshits, I. I. Rotenko, M. Yu. Soloveva, E. M. Yashchenko, O. M. Volotkevich, O. V. Gusarova, O. S. Ezhova, T. P. Lipinskaya, N. V. Udavidchik, A. V. Yurchenko, V. A. Yakovlev, V. A. Asiva, A. V. Kostyukovich, M. O. Streltsina, S. I. Khankevich, L. A. Lekunovich, Yu. M. Bogdan, Ya. K. Minich, Yu. P. Efimovich, V. A. Mishchenkov, E. Z. Gitsevich, T. E. Kolyago, T. G. Dunets, A. R. Mamedov, D. V. Posrednik, T. G. Gakun, V. S. Kostyunina, A. E. Makarevich, D. P. Ermakovich, D. A. Ramzaeva, E. S. Sinyavskaya and A. A. Vetoshkin.

The author is especially grateful to I. E. Samusenko for valuable advice in planning the study and recommendations on the design of the article. 


\section{Список использованных источников}

1. Основные результаты мониторинга белого аиста Ciconia ciconia в Воложинском районе Минской области (2004-2016 гг.) / А. В. Черноморец [и др.] // Зоологические чтения : сб. ст. междунар. науч.-практ. конф. (Гродно, 1517 марта 2017 г.) / редкол. : О. В. Янчуревич (гл. ред.) [и др.]. - Гродно, 2017. - С. 219-222.

2. Самусенко, И.Э. Значение поймы реки Припять для сохранения европейской популяции белого аиста Ciconia ciconia / И.Э. Самусенко // Проблемы рационального использования природных ресурсов и устойчивое развитие Полесья : сб. докл. Междунар. науч. конф. (Минск, 14-17 сент. 2016 г.) : в 2 т. / редкол. : В. Г. Гусаков (гл. ред.) [и др.]. Минск, 2016. - Т. 2. - С. 437-441.

3. Самусенко, И.Э. Предварительные итоги учета белого аиста Ciconia ciconia на территории Беларуси в 20142015 гг. / И.Э. Самусенко // Проблемы сохранения биологического разнообразия и использования биологических ресурсов : материалы ІІІ Междунар. конф., посвящ. 110-летию со дня рождения акад. Н.В. Смольского (7-9 окт. 2015 г., Минск) : в 2 ч. / редкол. : В. В. Титок [и др.]. - Минск, 2015. - Ч. 2. - С. 270-273.

4. Черноморец, А.В. Сравнительный анализ состояния и динамики популяции белого аиста в оптимальных и субоптимальных местообитаниях на территории Беларуси / А. В. Черноморец, И.Э. Самусенко // Актуальные проблемы зоологической науки в Беларуси : сб. ст. ХІ Зоол. Междунар. науч.-практ. конф. (г. Минск, 13 нояб. 2017 г.) : в 2 т. / редкол. : О. И. Бородин (гл. ред.) [и др.]. - Минск, 2017. - Т. 1. - С. 407-416.

5. Schüz, E. Zur Methode der Storchforschung / E. Schüz // Beiträge zur Vogelkunde. - Leipzig, 1952. - Bd. 2. - S. $287-298$.

6. Якубец, 3. Международная методика учета аистов и замечания о программе и направлениях дальнейших исследований / 3. Якубец, И. Самусенко // Аисты: распространение, экология, охрана : материалы II (Минск, окт. 1990 г.) и III (Канев, сент. 1991 г.) Всесоюз. совещ. рабочей группы по аистам Всесоюз. орнитол. о-ва / редкол. : И. Э. Самусенко (гл. ред.) [и др.]. - Минск, 1992. - С. 164-172.

\section{References}

1. Chernomorets A. V., Samusenko I. E., Grichik V. V., Balash A.V. Main results of monitoring of the White Stork Ciconia ciconia in the Volozhin district of the Minsk region (2004-2016). Zoologicheskie chteniya: sbornik statei mezhdunarodnoi nauchno-prakticheskoi konferentsii (Grodno, 15-17 marta 2017 goda) [Zoological readings: a collection of articles of the international scientific-practical conference (Grodno, March 15-17, 2017)]. Grodno, 2017, pp. $219-222$ (in Russian).

2. Samusenko I.E. The importance of the Pripyat river floodplain for the preservation of the European population of the White Stork Ciconia ciconia. Problemy ratsional'nogo ispol'zovaniya prirodnykh resursov i ustoichivoe razvitie Poles'ya: sbornik dokladov Mezhdunarodnoi nauchnoi konferentsii (Minsk, 14-17 sentyabrya 2016 goda). Tom 2 [Problems of rational use of natural resources and sustainable development of Polesie: a collection of reports of the International scientific conference (Minsk, September 14-17, 2016). Vol. 2]. Minsk, 2016, pp. 437-441 (in Russian).

3. Samusenko I. E. Preliminary results of accounting for White Stork Ciconia ciconia in Belarus in 2014-2015. Problemy sokhraneniya biologicheskogo raznoobraziya i ispol'zovaniya biologicheskikh resursov: materialy III Mezhdunarodnoi konferentsii, posvyashchennoi 110-letiyu so dnya rozhdeniya akademika N. V. Smol'skogo (7-9 oktyabrya 2015 g., Minsk). Chast' 2 [Problems of conservation of biological diversity and use of biological resources: Proceedings of the III International conference dedicated to the 110th anniversary of the birth of Academician N. V. Smolsky (7-9 October 2015, Minsk). Pt. 2]. Minsk, 2015, pp. 270-273 (in Russian).

4. Chernomorets A. V., Samusenko I.E. Comparative analysis of the status and dynamics of White Stork population in optimal and suboptimal habitats on the territory of Belarus. Aktual'nye problemy zoologicheskoi nauki v Belarusi: sbornik statei XI Zoologicheskoi Mezhdunarodnoi nauchno-prakticheskoi konferentsii (Minsk, 1-3 noyabrya 2017 goda). Tom 1 [Actual problems of zoological science in Belarus: a collection of articles of the XI Zoological International scientific and practical conference (Minsk, 1-3 November 2017). Vol. 1]. Minsk, 2017, pp. 407-416 (in Russian).

5. Schüz E. Zur Methode der Storchforschung. Beiträge zur Vogelkunde. Leipzig, 1952, Bd. 2, S. 287-298.

6. Yakubets Z., Samusenko I. International methodology for storing Storks and comments on the program and directions for further research. Aisty: rasprostranenie, ekologiya, okhrana: materialy II (Minsk, oktyabr' 1990 goda) i III (Kanev, sentyabr' 1991 goda) Vsesoyuznykh soveshchanii rabochei gruppy po aistam Vsesoyuznogo ornitologicheskogo obshchestva [Storks: distribution, ecology, protection: materials II (Minsk, October 1990) and III (Kanev, September 1991) All-Union meetings of the working group on storks of the All-Union Ornithological Society]. Minsk, 1992, pp. $164-172$ (in Russian).

\section{Информация об авторе}

Черномореи Анна Вадимовна - мл. науч. сотрудник. Научно-практический центр НАН Беларуси по биоресурсам (ул. Академическая, 27, 220072, г. Минск, Республика Беларусь). E-mail: avchernomorets@mail.ru

\section{Information about the author}

Anna V. Chernomorets - Junior researcher. Scientific and Practical Center for Bioresources of the National Academy of Sciences of Belarus (27, Akademicheskaya Str., 220072, Minsk, Republic of Belarus). E-mail: avchernomorets@mail.ru 